\title{
An anatomical investigation of rare upper limb neuropathies due to the Struthers' ligament or arcade: a meta-analysis
}

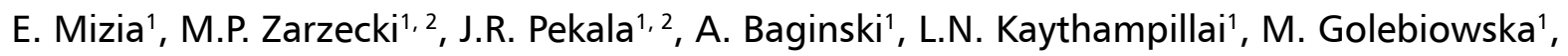
P.A. Pekala ${ }^{1,2}$, J.A. Walocha ${ }^{1,2}$, K.A. Tomaszewski, ${ }^{1,2}$

'Department of Anatomy, Jagiellonian University Medical College, Krakow, Poland 2International Evidence-Based Anatomy Working Group, Krakow, Poland

[Received: 4 March 2020; Accepted: 30 March 2020]

Background: The Struthers' ligament (SL) is a fibrous band that originates from the supracondylar humeral process and inserts into the medial humeral epicondyle, potentially compressing both the median nerve and brachial artery. The controversial Struthers' arcade (SA) is a musculotendinous band found in the distal end of the arm that might compress the ulnar nerve. This study aimed to evaluate the pooled prevalence estimate of the SL and SA, and their anatomical features. Materials and methods: A meticulous search of major electronic medical databases was carried out regarding both structures. Applicable articles (and all relevant references) were analysed. Data from the eligible articles was extracted and evaluated. The quality and the potential risk of bias in the included studies were assessed using the AQUA tool.

Results: The arcade was reported in 13 studies (510 arms), whereas the ligament in 6 studies (513 arms). The overall pooled prevalence estimate of the ligament was $1.8 \%$, and $52.6 \%$ for the arcade. Most frequently, the ulnar nerve was covered by a tendinous arcade (42.2\%). In all cases, the ligament inserted into the medial humeral epicondyle, but had various origins. Only 1 study reported compression of the median nerve by the ligament, whilst another contradicted this view. Conclusions: Although the SL is rare, and the SA is a valid anatomical entity (though with a variable presentation), clinically meaningful neurovascular entrapments caused by these structures are infrequent. Nonetheless, a better understanding of each may be beneficial for the best patient outcomes. (Folia Morphol 2021; 80, 2: 255-266)

Key words: Struthers' arcade, Struthers' ligament, meta-analysis

\section{INTRODUCTION}

Neurovascular compressions of the upper limb may have highly variable clinical manifestations including pain, numbness, weakness and muscular atrophy [1]. Fortunately, the entrapment site is often easily localised with careful physical examination and/or radio- graphic imaging [1]. Rare instances of such syndromes have been attributed to two anatomical structures: the Struthers' ligament (SL) and the Struthers' arcade (SA). These two structures are frequently confused, and some contention exists pertaining to their prevalence. Sir John Struthers described 9 arcades (a series of mus-

Address for correspondence: E. Mizia, MD, PhD, Department of Anatomy, Jagiellonian University Medical College, ul. Kopernika 12, 31-034 Kraków, Poland, tel/fax: +48 1242295 11, e-mail: ewa.mizia@gazeta.pl

This article is available in open access under Creative Common Attribution-Non-Commercial-No Derivatives 4.0 International (CC BY-NC-ND 4.0) license, allowing to download articles and share them with others as long as they credit the authors and the publisher, but without permission to change them in any way or use them commercially. 
culotendinous and fibrous arches) in the arm - eight associated with the median nerve, and one with the ulnar nerve [2]. The eighth of this series was a fibrous structure known as the $\mathrm{SL}$, and attached to a bony spur on the humerus. The ninth, known nowadays as the SA, was a fibrous band at the brachial fascia, and not anchored to any bony elements [2].

The SL typically begins at a bony projection approximately two inches above the medial epicondyle on the anteromedial aspect of the humerus, labelled the supracondylar process (or spur), which can usually be identified on X-ray imaging [33]. The ligament itself extends from this process, and attaches to the medial humeral epicondyle. The brachial artery, the median nerve, or both can run beneath this fibrous band. Initial descriptions suggested a prevalence of $1 \%$ in the human population [3]. Although it is an uncommon feature, its existence is undisputed. However, it has been implicated in causing a rare compression of the neurovascular entities, causing paraesthesia and numbness associated with forearm claudication or median nerve dysfunction [5]. A surgical procedure involving release of the entrapped element, in combination with excision of the SL and its bony spur, effectively eliminates all the clinical symptoms permanently [1].

The SA is a more disputed anatomical structure, with highly variable descriptions and classifications [12]. Kane et al. [24] were the first to apply Struthers' work and define the fibrous canal (definition as applied herein) with a roof formed by a deep fascial thickening, an anterior border at the medial intermuscular septum, and a lateral border at the humerus and the muscular fibre covering of the triceps brachii. Several subsequent reports have supported the existence of this structure to various degrees; however, the discrepancies in findings may be attributable to the differences in definition [15, 20,34]. Alternatively, other authors $[7,32,40]$ debate its existence altogether, suggesting that the previous findings are only anatomical variations of the intermuscular septum and the forearm fascia. As such, it is important not only to assess the prevalence of this structure, but also the clinical presentation, and its possible variations [37]. The disagreements regarding the SA extend to its role as a possible site for entrapment. Although it is unlikely as a primary site for entrapment, most tend to agree that it is a factor in recurrent ulnar neuropathy after an anterior transposition of the nerve at the elbow $[14,25,31]$.
This study seeks to evaluate the differences from an anatomical perspective, establish the pooled prevalence estimate (PPE) of both the SL and the SA, assess their involvement in the median/ulnar nerve entrapments, respectively, and provide the answer as to whether the disputed SA is a valid anatomical structure. Becoming acquainted with the said variants is of immense importance to physicians encountering unusual upper limb neural entrapments that cannot be explained by more commonly existing pathologies.

\section{MATERIALS AND METHODS}

This study is a systematic review and meta-analysis, level of evidence: II.

\section{Search strategy}

An extensive search on the SA and the SL, as well as their anatomy, was conducted on PubMed, Embase, ScienceDirect and Web of Knowledge databases. The following search terms applied: "Struthers' ligament" OR "Ligament of Struthers" OR "supracondylar canal" OR "supracondylar spur" OR "supracondylar process" OR "supratrochlear spur" OR "avian spur" OR "Arcade of Struthers" OR "Struthers' Arcade." No restrictions were set to date or language of the original publication. Additionally, all references in the included articles were assessed to identify any other potentially eligible studies.

\section{Study selection criteria}

Eligibility for inclusion was governed by the following criteria: cadaveric or imaging studies containing information about the SL or the SA - both anatomically and clinically. Case reports, conference abstracts, letters to editors, reviews, or studies containing irrelevant or incomplete data about the SL or the SA were not considered.

\section{Eligibility assessment}

The authors (E.M., M.P.Z., J.R.P., L.N.K., M.G.) completed an independent review of all the included studies. Any disagreements were settled by consensus, where necessary also involving a consultation with the authors of the original study. Any studies published in a language not fluently spoken by the reviewing authors were translated by medical professionals fluent in both the original language of the manuscript and English.

\section{Data extraction}

The extraction of data from the included studies was performed separately by independent reviewers. 
The following data was extracted: country of study origin, method, total number of patients/specimens with the SL/SA, as well as characteristics of modality. Elements of interest included laterality, typical vs. atypical presentation and type, morphology, relation to associated nerve, extent of compression, and insertion (the $\mathrm{SL}$ ).

\section{Quality assessment}

The quality assessment was completed by independent reviewers by utilising the Anatomical Quality Assurance tool (the AQUA Tool), a versatile instrument capable of appraising anatomical studies [23]. This method employed a "risk of bias" table assessing the five domains: (1) Aim and subject characteristics; (2) Study design; (3) Characterisation of methods; (4) Descriptive anatomy; and (5) Results reporting. Each criterion level of bias was deemed "High", "Low," or "Unclear" in accordance to "Yes" or "No" answers to specific determining questions. Conditions where "Yes" was selected identified a "Low" risk of bias, whereas a "No" answer suggested a "High" risk. Any disagreements were resolved with discussions, or by involving an additional reviewer.

\section{Statistical analysis}

All the extracted data was processed using MetaXL version 5.3 (EpiGear International, Australia) as a meta-analysis with random-effects model. The PPE of the SL and the SA, respectively, was the primary measure of this study, with subsequent analysis by subgroups.

Heterogeneity was tested for using the $\chi^{2}$ and Higgins $I^{2}$ tests. A significant heterogeneity was identified from a $p$-value of $<0.10$ in the $\chi^{2}$ test [22]. Heterogeneity was determined from the $I^{2}$ test according to the following scheme: $0 \%$ to $40 \%$ may not be present; $30 \%$ to $60 \%$ possible indications of moderate heterogeneity; $50 \%$ to $90 \%$ likely meaningful heterogeneity; and $75 \%$ to $100 \%$ suggests considerable heterogeneity [22].

In order to investigate possible sources of heterogeneity, subgroup analyses were completed to consider the effect of geographical distribution and modality. Confidence intervals were utilised to illustrate any determined statistical differences between two or more subgroups. Conclusions regarding statistical insignificance could be drawn if any such intervals overlapped [22].

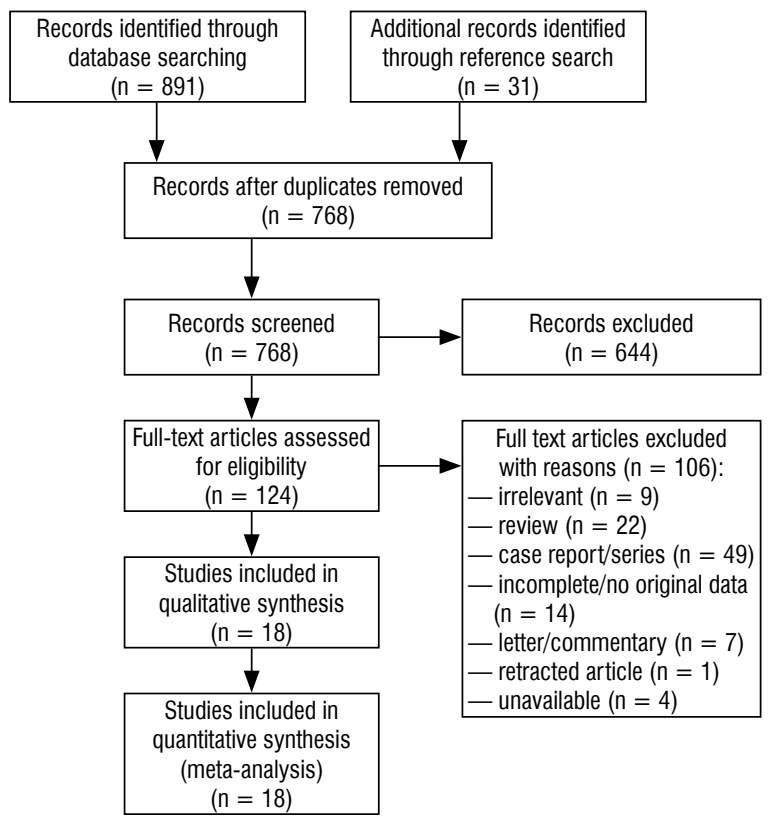

Figure 1. The Preferred Reporting Items for Systematic Reviews and Meta-Analyses (PRISMA) flow chart.

\section{RESULTS}

\section{Study identification}

The study selection process is illustrated in Figure 1. Initially, 891 articles were identified according to the specified parameters across all major electronic databases. Additional 31 articles were included when the cited articles of the previous group were checked. Of all the articles, 124 were identified as potentially meeting the inclusion criteria, from which 108 were deemed ineligible, for reasons such as being case reports/series, containing irrelevant/incomplete/no original data or were letters/commentaries to the editor. Therefore, 18 studies were utilised for this meta-analysis (5 pertaining to the SL, 12 to the SA and 1 study to both the SA and the SL).

\section{Characteristics of the included studies}

The tables outline the characteristics of the included studies in this meta-analysis. The 6 studies pertaining to the SL ( $\mathrm{n}=513$ upper limbs) were conducted from 1983 to 2017. The 13 studies reporting on the SA ( $n=510$ upper extremities) were published from 1991 to 2016. The prevalence rates of the relevant structures are reported in (Tables 1, 2).

\section{Prevalence of the SL}

A complete assessment of the SL was completed according to a subgroup analysis by geography, 
Table 1. The characteristics of the included studies for the Struthers ligament (SL)

\begin{tabular}{lcccc}
\hline Study & Country & Type of study & Number of limbs & Prevalence (\%) \\
\hline Bilecenoglu et al., 2005 [8] & Turkey & Cadaveric & 30 & 3.3 \\
Caetano et al., 2017 [11] & Brazil & Cadaveric & 60 & 0.1 \\
Dellon, 1987 [17] & USA & Cadaveric & 43 & 0.0 \\
Gessini et al., 1983 [19] & Italy & Surgery & 238 & 0.4 \\
Gunther et al., 1993 [21] & USA & Cadaveric & 38 & 2.6 \\
Dellon, 1986 [16] & USA & Cadaveric & 104 & 0.0 \\
\hline
\end{tabular}

Table 2. The characteristics of the included studies for the Struthers arcade

\begin{tabular}{lcccc}
\hline Study & Country & Type of study & Number of limbs & Prevalence (\%) \\
\hline Al-Oattan and Murray, 1991 [2] & Canada & Cadaveric & 25 & 68.0 \\
Bartels et al., 2003 [7] & Netherlands & Cadaveric & 10 & 0.0 \\
Caetano et al. 2017 [12] & Brazil & Cadaveric & 40 & 100.0 \\
Gonzalez et al., 2001 [20] & USA & Cadaveric & 39 & 66.7 \\
Mirza et al., 2014 [27] & USA & Cadaveric & 26 & 7.7 \\
Poujade et al., 2014 [30] & France & Cadaveric & 18 & 33.3 \\
Siqueira and Martins, 2005 [32] & Brazil & Cadaveric & 60 & 18.3 \\
Tubbs et al., 2011 [38] & USA & Cadaveric & 30 & 86.7 \\
Tiyaworanan et al., 2010 [37] & Thailand & Cadaveric & 62 & 85.5 \\
Von Schroeder and Scheker, 2003 [39] & Canada & Cadaveric & 14 & 100.0 \\
Yoshida et al., 2014 [41] & Japan & Surgery & 82 & 1.2 \\
Zhong et al., 2016 [42] & China & Cadaveric & 64 & 57.8 \\
Zhong et al., 2016 [42]* & China & Medical imaging & 40 & 50.0 \\
\hline
\end{tabular}

*One study was conducted as a cadaveric and a medical imaging investigation on two separate populations

Table 3. The modality and geographical distribution of the Struthers ligament (SL) studies

\begin{tabular}{lcccc}
\hline Subgroup & $\begin{array}{c}\text { Number of studies } \\
\text { (no. of subjects) }\end{array}$ & $\begin{array}{c}\text { Pooled prevalence of SL; } \\
\%(\mathbf{9 5 \%} \mathbf{C l})\end{array}$ & 12; \% (95\% CI) & Cochran's 0, p-value \\
\hline Overall & $6(513)$ & $1.8(0.1-5.2)$ & $70.7(31.7-87.4)$ & $17.1, \mathrm{p}=0.004$ \\
Cadaveric & $5(275)$ & $2.3(0.0-7.4)$ & $71.7(28.6-88.8)$ & $14.1, \mathrm{p}=0.007$ \\
North America & $3(185)$ & $0.8(0.0-2.6)$ & $17.1(0.0-91.4)$ & $2.4, \mathrm{p}=0.299$ \\
\hline
\end{tabular}

$\mathrm{Cl}$ - confidence interval

Table 4. Prevalence of the Struthers ligament (SL) in respect to side

\begin{tabular}{lcccc}
\hline Number of studies (no. of subjects with SL) & Right side SL; \% (95\% CI) & Left side SL; \% (95\% Cl) & 1; \% (95\% CI) & Cochran's 0, p-value \\
\hline $4(9)$ & $55.8(24.7-84.8)$ & $44.2(15.2-75.3)$ & $0.0(0.0-82.7)$ & $2.7, p=0.449$ \\
\hline $\mathrm{Cl}-$ confidence interval & &
\end{tabular}

$\mathrm{Cl}$ - confidence interval

laterality, reported median nerve compression, and insertion, the results of which can be found, respectively. The geographical analysis differentiated all the studies (PPE 1.8\%; 95\% confidence interval [CI] $0.1-5.2 \%$ ) from cadaveric studies (PPE 2.3\%; 95\% $\mathrm{Cl} 0.0-7.4 \%)$, as well as those reporting from North America (PPE 0.8\%; 95\% Cl 0.0-2.6\%) (Table 3).
Four studies (Table 4) included which side the SL was present on. The SL appears slightly more often on the right side $(55.8 \% ; 95 \% \mathrm{Cl} 24.7-84.8)$ than the left (44.2\%; 95\% Cl 15.2-75.3).

Gessini's surgical study [19] from Italy supported the SL as a contributor to median nerve compression, whereas Gunther's cadaveric study [21] 
Table 5. The median nerve compression by the Struthers ligament (SL)

\begin{tabular}{lcccc}
\hline Study & Country & Type of study & Number of limbs with SL & Prevalence of median nerve compression (\%) \\
\hline Gessini et al., 1983 [19] & Italy & Surgery & 1 & 100.0 \\
Gunther et al., 1993 [21] & USA & Cadaveric & 1 & 0.0 \\
\hline
\end{tabular}

Table 6. The insertion points of the Struthers ligament (SL)

\begin{tabular}{lcccc}
\hline Study & Country & Type of study & Number of limbs with SL & Prevalence of medial epicondyle insertion (\%) \\
\hline Bilecenoglu et al., 2005 [8] & Turkey & Cadaveric & 1 & 100.0 \\
Gessini et al., 1983 [19] & Italy & Surgery & 1 & 100.0 \\
Gunther et al., 1993 [21] & USA & Cadaveric & 1 & 100.0 \\
\hline
\end{tabular}

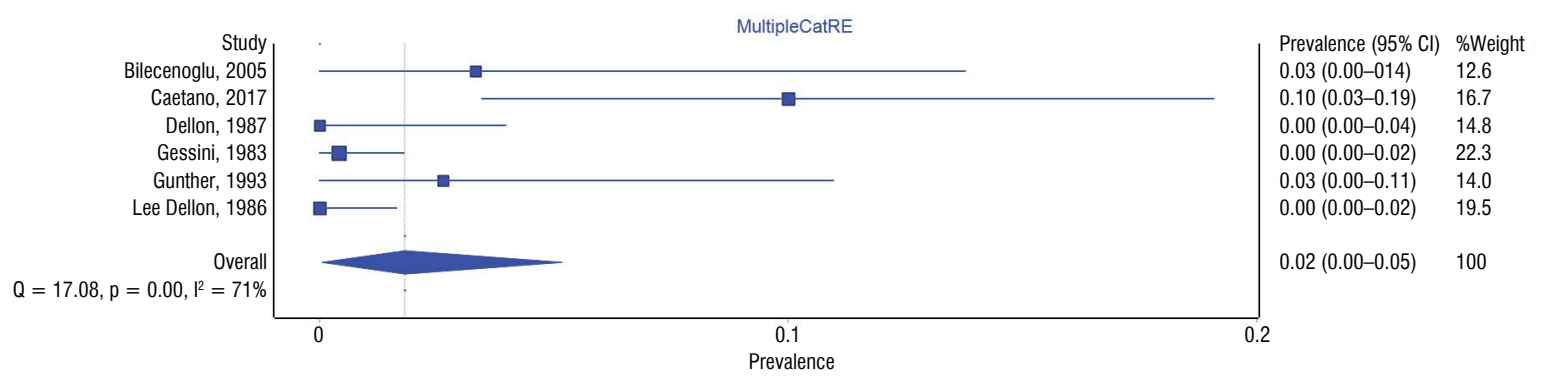

Figure 2. Prevalence of the Struthers ligament forest plot; $\mathrm{Cl}$ - confidence interval.

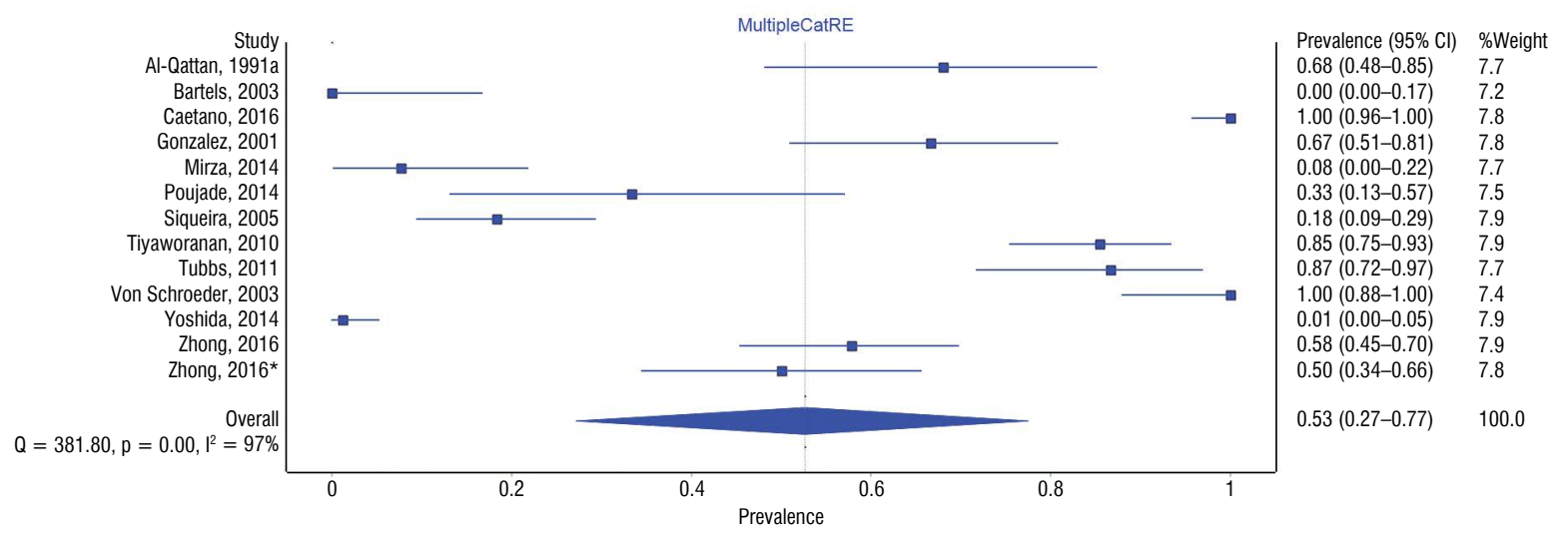

Figure 3. Prevalence of the Struthers arcade forest plot; *one study was conducted as a cadaveric and a medical imaging investigation on two separate populations; $\mathrm{Cl}$ - confidence interval.

from the United States did not support this finding (Table 5).

Lastly, 3 studies (Table 6) outlined the distal insertion point of the SL. In all cases, the SL was found to terminate at the medial humeral epicondyle. Notwithstanding, the origin of the SL varied in all those three instances, as in 1 case it was attached to the supracondylar humeral process, in another into the anteromedial surface of the humerus (with no bony spur present) and into the brachialis muscle in the last case (Fig. 2).

\section{Prevalence of the SA}

Similarly to the analysis of the $\mathrm{SL}$, assessment of the SA was divided by subgroups - geographical prevalence, atypical prevalence, atypical type, morphology, relation to the ulnar nerve, and ulnar nerve compression. 
Table 7. The modality and geographical distribution of the Struthers arcade (SA) studies

\begin{tabular}{lcccc}
\hline Subgroup & Number of studies (no. of subjects) & Pooled prevalence of SA; \% (95\% Cl) & 1; \% (95\% Cl) & Cochran's 0, p-value \\
\hline Overall & $13(510)$ & $52.6(27.1-77.5)$ & $96.9(95.8-97.7)$ & $381.8, p<0.001$ \\
Cadaveric & $11(388)$ & $59.6(35.0-82.1)$ & $95.4(93.4-96.8)$ & $218.4, p<0.001$ \\
North America & $5(134)$ & $69.4(32.3-97.1)$ & $93.7(88.3-96.7)$ & $64.0, p<0.001$ \\
Asia & $4(248)$ & $45.2(0.0-94.2)$ & $98.2(97.1-98.9)$ & $169.7, p<0.001$ \\
South America & $2(100)$ & $68.0(0.0-100.0)$ & $99.1(98.1-99.5)$ & $105.6, p<0.001$ \\
Europe & $2(28)$ & $15.1(0.0-59.1)$ & $83.2(30.0-96.0)$ & $6.0, p=0.015$ \\
\hline
\end{tabular}

$\mathrm{Cl}$ - confidence interval

Table 8. The definitions of the Struthers arcade applied in this meta-analysis.

\begin{tabular}{|c|c|c|}
\hline Author & Year & Definition \\
\hline Kane et al. [24] & 1973 & $\begin{array}{l}\text { Fibrous canal with roof formed by a deep fascial thickening, an anterior border at the medial } \\
\text { intermuscular septum, and a lateral border at the humerus and the muscular fibre covering } \\
\text { of the triceps brachii. (Considered as the "classical" in this study.) }\end{array}$ \\
\hline Al-Oattan and Murray [2] & 1991 & $\begin{array}{l}\text { "Classical" definition provided by Kane et al. } \\
\text { OR } \\
\text { Multiple ligaments of the thickened deep fascia and medial intermuscular septum } \\
\text { passing superficial and deep to the ulnar nerve } \\
\text { OR } \\
\text { Roof formed by the triceps muscular fibres alone. } \\
\text { (Both considered as the "atypical" in this study.) }\end{array}$ \\
\hline Tubbs et al. [38] & 2011 & $\begin{array}{c}\text { Thickening of the brachial fascia } \\
\text { OR } \\
\text { Thickening of the internal brachial ligament } \\
\text { OR } \\
\text { Thickening of the medial intermuscular septum. } \\
\text { (All three considered as the "atypical" in this study.) }\end{array}$ \\
\hline
\end{tabular}

Table 9. Prevalence of the classical and atypical Struthers arcade

\begin{tabular}{lcccc}
\hline Type & $\begin{array}{c}\text { Number of studies } \\
\text { (no. of subjects) }\end{array}$ & $\begin{array}{c}\text { Pooled prevalence; } \\
\%(\mathbf{9 5 \%} \mathbf{~ C l )}\end{array}$ & 12; \% (95\% Cl) & Cochran's 0, p-value \\
\hline Classical & $8(142)$ & $72.8(30.0-100.0)$ & $95.8(93.5-97.2)$ & $165.6, p<0.001$ \\
Atypical & $8(142)$ & $27.2(0.0-70.0)$ & $95.8(93.5-97.2)$ & $165.6, p<0.001$ \\
\hline
\end{tabular}

$\mathrm{Cl}$ - confidence interval

The geographical analysis separated all the studies (PPE 52.6\%; 95\% Cl 27.1-77.5\%) from cadaveric studies (PPE 59.6\%; 95\% Cl 35.0-82.1\%), as well as those reporting from North America (PPE 69.4\%; 95\% Cl 32.3-97.1\%), Asia (PPE 45.2; 95\% Cl 0.0-94.2\%), South America (PPE 68.0\%; 95\% Cl 0.0-100.0\%), and Europe (PPE 15.1\%; 95\% Cl 0.0-59.1\%) (Fig. 3, Table 7).

The formal description of the SA by Kane et al. [24] (a fibrous canal with a roof formed by a deep fascial thickening, an anterior border at the medial intermuscular septum, and a lateral border at the humerus and the muscular fibre covering of the triceps brachii) did not always apply to the findings of certain included studies due to its variability in presentation $[2,27,32,38]$. The variant definitions of the SA can be found in Table 8. Since most of the authors described their SA in accordance with the definition stated by Kane et al. [24], we applied this term as the classical type in opposition to the atypical SAs, found and described less commonly. All the typical and unusual SAs encountered in analysed studies fit into one of the definitions from Table 8 . Table 9 presents the PPE of the typical and atypical SAs, and Table 10 reports the types of the atypical SAs (when reported in the respective studies). The most common of the atypical types is a thickening of the brachial fascia, found in $39.3 \%$ (95\% Cl $0.0-89.0 \%)$ of the reported 38 structures.

The morphology of the SA was found to be mostly musculotendinous (PPE 54.2; 95\% Cl 12.6-89.1\%), or 
Table 10. Types of the atypical Struthers arcade

\begin{tabular}{lcccc}
\hline Type & $\begin{array}{c}\text { Number of studies } \\
\text { (no. of subjects) }\end{array}$ & $\begin{array}{c}\text { Pooled prevalence; } \\
\%(95 \% \text { CI) }\end{array}$ & l'; \% (95\% CI) & Cochran's 0, p-value \\
\hline $\begin{array}{l}\text { Multiple ligaments of thickened deep fascia and } \\
\text { medial intermuscular septum }\end{array}$ & $4(38)$ & $16.6(0.0-62.2)$ & $83.5(58.3-93.5)$ & $18.2, \mathrm{p}<0.001$ \\
Roof formed by the triceps muscular fibres alone & $4(38)$ & $24.1(0.0-72.8)$ & $83.5(58.3-93.5)$ & $18.2, \mathrm{p}<0.001$ \\
Thickening of the brachial fascia & $4(38)$ & $39.3(0.0-89.0)$ & $83.5(58.3-93.5)$ & $18.2, \mathrm{p}<0.001$ \\
Thickening of the internal brachial ligament & $4(38)$ & $9.6(0.0-49.9)$ & $83.5(58.3-93.5)$ & $18.2, \mathrm{p}<0.001$ \\
Thickening of the medial intermuscular septum & $4(38)$ & $10.4(0.0-51.6)$ & $83.5(58.3-93.5)$ & $18.2, \mathrm{p}<0.001$ \\
\hline
\end{tabular}

$\mathrm{Cl}$ - confidence interval

Table 11. Morphological types of the Struthers arcade

\begin{tabular}{lcccc}
\hline Type & $\begin{array}{c}\text { Number of studies } \\
\text { (no. of subjects) }\end{array}$ & $\begin{array}{c}\text { Pooled prevalence; } \\
\%(\mathbf{9 5 \%} \text { Cl) }\end{array}$ & 12; \% (95\% CI) & Cochran's 0, p-value \\
\hline Musculotendinous & $10(193)$ & $54.2(12.6-89.1)$ & $96.0(94.3-97.3)$ & $227.2, p<0.001$ \\
Tendinous & $10(193)$ & $38.5(3.5-77.3)$ & $96.0(94.3-97.3)$ & $227.2, p<0.001$ \\
Muscular & $10(193)$ & $7.2(0.0-33.5)$ & $96.0(94.3-97.3)$ & $227.2, p<0.001$ \\
\hline
\end{tabular}

$\mathrm{Cl}$ - confidence interval

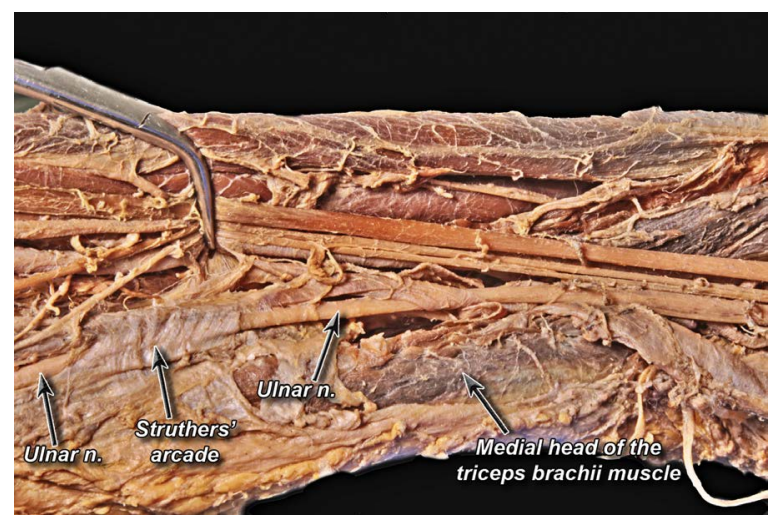

Figure 4. A tendinous Struthers arcade found during a routine cadaveric dissection.

otherwise tendinous (PPE 38.5; 95\% Cl 3.5-77.3\%), or muscular (PPE 7.2; 95\% Cl 0.0-33.5\%) (Table 11). Examples of the SAs found during our own routine cadaveric examinations are presented on Figure 4 (a tendinous arcade) and Figure 5 (a musculotendinous arcade).

The various relations of the SA to the ulnar nerve are shown in Table 12, where it most typically presented as a tendinous arcade passing over the ulnar nerve (PPE 42.2; 95\% Cl 2.5-77.9\%). Table 13 presents the findings of the 3 studies concerning the prevalence of ulnar nerve compression. Forty limbs from 1 study [12] were reported to show no compression, whereas all the SAs of Mirza et al. [27] and

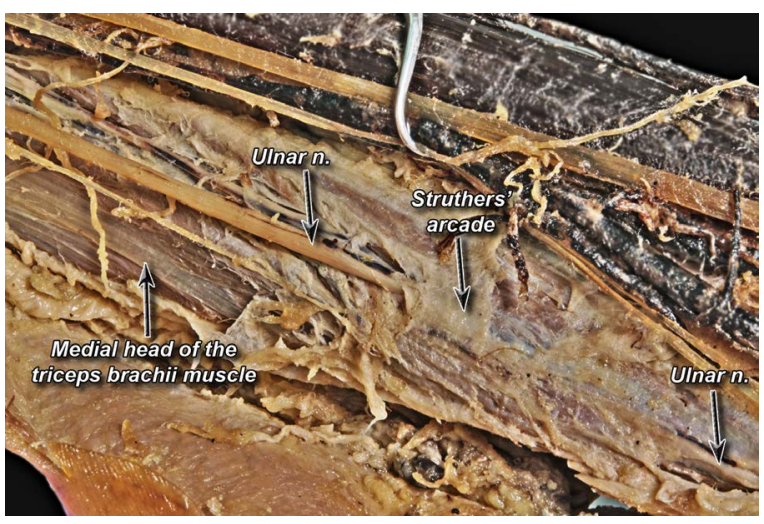

Figure 5. A musculotendinous Struthers arcade found during a routine cadaveric dissection.

Yoshida et al. [41] were associated with the ulnar nerve compression.

\section{Risk of bias analysis}

The complete appraisal of the included studies in terms of the risk of bias they pose is presented in Table 14. All in all, the vast majority of the studies were assessed as having a "High" risk of bias in Domains 1 and 3, due to the lack of complete information about the patients' baseline characteristics and demographics, as well as the specialty and experience of the scientists in charge of a particular part of the study. Domains 2 and 5 were evaluated as being at "Low" risk of bias for all the included studies. Nonetheless, 
Table 12. Relation of the Struthers arcade to the ulnar nerve

\begin{tabular}{|c|c|c|c|c|}
\hline Type & $\begin{array}{c}\text { Number of studies } \\
\text { (no. of subjects) }\end{array}$ & $\begin{array}{c}\text { Pooled prevalence; } \\
\%(95 \% \mathrm{CI})\end{array}$ & $\mathrm{I}^{2} ; \%$ (95\% Cl) & $\begin{array}{l}\text { Cochran's } 0, \\
\text { p-value }\end{array}$ \\
\hline Musculotendinous arcade covers the nerve & $9(193)$ & $34.2(0.0-71.6)$ & $96.5(94.9-97.6)$ & $227.2, p<0.001$ \\
\hline Tendinous arcade passing over the ulnar nerve & $9(193)$ & $42.2(2.5-77.9)$ & $96.5(94.9-97.6)$ & $227.2, p<0.001$ \\
\hline Triceps muscle covers the nerve & $9(193)$ & $13.8(0.0-43.9)$ & $96.5(94.9-97.6)$ & $227.2, p<0.001$ \\
\hline The ulnar nerve passing anteriorly to the arcade & $9(193)$ & $2.5(0.0-21.9)$ & $96.5(94.9-97.6)$ & $227.2, p<0.001$ \\
\hline Triceps aponeurosis covers the nerve & $9(193)$ & $3.6(0.0-24.9)$ & $96.5(94.9-97.6)$ & $227.2, p<0.001$ \\
\hline $\begin{array}{l}\text { Multiple ligaments of thickened deep fascia and medial inter- } \\
\text { muscular septum pass superficially and deeply to the nerve }\end{array}$ & $9(193)$ & $3.7(0.0-25.2)$ & $96.5(94.9-97.6)$ & $227.2, p<0.001$ \\
\hline
\end{tabular}

$\mathrm{Cl}$ - confidence interval

Table 13. The ulnar nerve compression by the Struthers arcade (SA)

\begin{tabular}{lcccc}
\hline Study & Country & Type of study & Number of limbs with SA & $\begin{array}{c}\text { Prevalence of ulnar } \\
\text { nerve compression (\%) }\end{array}$ \\
\hline Caetano et al. 2017 [12] & Brazil & Cadaveric & 40 & 0.0 \\
Mirza et al., 2014 [27] & USA & Cadaveric & 2 & 100.0 \\
Yoshida et al., 2014 [41] & Japan & Surgery & 1 & 100.0 \\
\hline
\end{tabular}

Table 14. The risk of bias analysis

\begin{tabular}{|c|c|c|c|c|c|}
\hline \multirow[t]{2}{*}{ Study } & \multicolumn{5}{|c|}{ Risk of bias } \\
\hline & $\begin{array}{l}\text { Objective(s) and study } \\
\text { characteristics }\end{array}$ & Study design & $\begin{array}{c}\text { Methodology } \\
\text { characterisation }\end{array}$ & $\begin{array}{c}\text { Descriptive } \\
\text { anatomy }\end{array}$ & $\begin{array}{l}\text { Reporting of } \\
\text { results }\end{array}$ \\
\hline Al-Qattan and Murray, 1991 [2] & High & Low & High & Low & Low \\
\hline Bartels et al., 2003 [7] & High & Low & High & Low & Low \\
\hline Bilecenoglu et al., 2005 [8] & High & Low & High & Low & Low \\
\hline Caetano et al., 2017 [11] & High & Low & High & Low & Low \\
\hline Caetano et al., 2017 [12] & High & Low & High & Low & Low \\
\hline Dellon et al, 1987 [17] & High & Low & High & Low & Low \\
\hline Gessini et al., 1983 [19] & High & Low & High & Low & Low \\
\hline Gonzalez et al., 2001 [20] & High & Low & High & Low & Low \\
\hline Gunther et al., 1993 [21] & High & Low & High & Low & Low \\
\hline Dellon 1986 [16] & High & Low & High & Low & Low \\
\hline Mirza et al., 2014 [27] & High & Low & High & Low & Low \\
\hline Poujade et al., 2014 [30] & High & Low & High & Low & Low \\
\hline Siqueira and Martins, 2005 [32] & Low & Low & High & Low & Low \\
\hline Tiyaworanan et al., 2010 [37] & High & Low & High & High & Low \\
\hline Tubbs et al., 2011 [38] & High & Low & High & Low & Low \\
\hline Von Schroeder and Scheker, 2003 [39] & High & Low & High & Low & Low \\
\hline Yoshida et al., 2014 [41] & High & Low & High & High & Low \\
\hline Zhong et al., 2016 [42] & High & Low & High & Low & Low \\
\hline
\end{tabular}

Domain 4 had two studies at "High" risk of bias due to them not specifying their definition of the SA (Table 14).

\section{DISCUSSION}

This study aims to clarify the differences between the $S L$ and the SA, and investigate their respective 
properties in a clinically relevant manner. Disagreements in prior publications exist, promoting a poor understanding of these structures and their implications in the treatment of upper limb neuropathies [11]. In order to improve patient outcomes during the associated procedures, this meta-analysis attempted to evaluate the SL and the SA in terms of their PPE, anatomical features (such as e.g. morphology), and relation to the median and ulnar nerves, respectively.

Clinicians must consider the possible involvement of these two structures in their practice - especially in surgeries. The $\mathrm{SL}$ is rare, and is typically associated with the brachial artery and/or the median nerve. Due to its low prevalence, it is infrequently being considered in the differential diagnosis as a cause of entrapment [21]. Also, even if present (when identified by radiographs) it may not necessarily be the origin of the symptoms [21]. The SA is a valid structure, most typically presenting as a musculotendinous band associated with the ulnar nerve, but has extensive variability. Primary entrapment has not been described, but it has been largely implicated in failed cubital tunnel surgery, or otherwise during the anterior transposition of the ulnar nerve, which may be the result of unsuccessful decompression or formation of a new site of compression [15, 18, 32]. Since both structures have been suggested to be involved in neuropathies, it is of immense importance for medical professionals to get acquainted with their variants and consider them in the differential diagnoses. This recommendation is especially valid in cases which cannot be explained by more commonly prevalent conditions, e.g. cubital tunnel syndrome in case of the ulnar nerve entrapment.

Henceforth, patients presenting with unusual cases (such as with the SL or the SA involvement) may be treated more accurately by medical professionals acquainted with their infrequent causes, possibly mitigating the risk of permanent nerve injuries. Compressions to the median, radial, or ulnar nerve, which occur especially when such bands of fibrous or muscular tissue traverse them, may lead to upper limb entrapment peripheral neuropathies [8]. Ulnar nerve neuropathies at the elbow are important in particular, as they are the second most common entrapment neuropathy in adults [10].

The $S L$ is a consistently reported structure, and our PPE findings (1.8\%) are in line with that of previous descriptions $[3,5,29,35]$. These results support that this structure is vestigial, and is likely analogous to the latissimocondyloideus muscle found in climbing animals $[3,9]$, which serves to protect the neurovascular bundle and provides attachment for the pronator teres muscle by forming an end-epitrochlear foramen [3].

Although we report that it may be slightly more prevalent on the right side, this result is only based on 9 cases, so the statistical power is not significant. Only 2 reports were included in this analysis concerning the prevalence of median nerve compression as a result of the $\mathrm{SL}$, with one supporting and one opposing this view $[19,21]$. Therefore no appropriate conclusions can be drawn. However, a series of cases have been described where radiological examination of a patient complaining of paraesthesia and numbness have identified the characteristic spur, and subsequent release surgery has yielded reduced or eliminated clinical symptoms following recovery $[1,4,5]$. Ay et al. [6] describe success using Barnard and McCoy classical approach to remove the periosteum of the spur, the binding fibres of the pronator teres muscle, and the fibrous extension.

Although entrapment syndromes are typically evaluated using magnetic resonance imaging and electromyography, their application in the SL-related conditions is poorly described $[4,13]$. Palpation of the bony process may or may not be possible, so it cannot be used as an indication for investigative imaging [9] . In addition, rare instances have been reported where the SL was found associated with only a minimal protrusion, or none whatsoever [35]. Gunther et al. [21] report that the supracondylar spur is most typically an incidental finding on radiography, and that no surgical corrections should be made without any clinical complaints present. Furthermore, a clinician should not automatically assume that the SL (if present) is responsible for any neuropathies prior to investigation. However, the surgeon should be conscious of these structures during surgical exploration. Also, it may be beneficial to recognize that the $S L$ likely inserts into the medial humeral epicondyle (possibly lending aid to the identification of this rare anatomical variant) as per all the reports evaluated herein $[8,19,21]$.

Since the overall PPE of the SL is very low, it will ultimately be a rare cause of entrapment. Importantly, Laha et al. [26] define a simple differentiation of the median nerve entrapment by the SL and its bony ligament from the more common pronator syndrome because of pronator teres weakness found in the latter.

Lastly, Taylor et al. [36] discuss the possibility of using the SL (associated with the coracobrachialis 
muscle) during restoration of normal facial expression procedures in the longstanding facial paralysis, as it might be used to replace the orbicularis oris muscle and eliminate the deviation of the lips towards the unaffected side whilst smiling. Nonetheless, additional research is required on this matter to ensure the development of safe and effective treatments.

Many previous reports have had opposing views on whether or not the SA is a true structure, or just a product of a specific method of dissection, and further still, if its presence could be related to entrapment $[7,12,16,39]$. The results of the study herein suggest that the SA can be found in most individuals, but that its presentation is highly variable, described in Tables 8-11. Al-Qattan and Murray [2], Mirza et al. [27], Siqueira and Martins [32] and Tubbs et al. [38], all describe at least some occurrence of an atypical SA, differing by the source of the thickened fascia or musculotendinous band. Even more inconsistency lies in the morphology of the SA, where most tended to be musculotendinous, but a large proportion was still found to be solely tendinous or muscular. Another factor may be, as Bartels et al. [7] suggest, where any dissection can be conducted to replicate a fibrous structure depending on the stepwise technique. However, earlier reports on the arcade clearly differentiate the absence or presence with images and descriptions of their division [34].

The course of the SA was described in 9 studies, and it most frequently presents as either a musculotendinous or tendinous arcade covering or passing over the ulnar nerve. Only 3 included studies specifically outlined the prevalence of the ulnar nerve compression from the SA, the results of which either suggested a $100 \%$ association with compression or $0 \%$. Therefore, an extensively variable presentation of this structure may be likely, suggesting a difficulty in differentiating the possible interactions of the SA.

Firstly, inaccurate reporting may be the result of confusion between the SL and the SA [11] as the two similarly named structures appear in the same region. This clarification is imperative for future consistency.

Al-Qattan and Murray [2] report that when performing a procedure to release an entrapped nerve, an atypical SA with a roof of multiple ligaments may have resulted in further entrapment, and that ligaments passing deep to the ulnar nerve should also be released at their insertions. Bartels et al. [7] and Dellon [16] claim to have never observed any such tendinous arches during their nerve entrapment release surgeries, and suggest that any observed bands are likely the result of improper release of the brachial fascial sheath during the previously undertaken anterior transposition of the ulnar nerve that now became the fibrotic point of compression of the nerve. Bartels et al. [7] also suggest that the edge of the sheath that was cut might become more fibrotic and hence resemble the structure known as the SA. Dellon [16] continues to suggest that an appropriate incision for the cubital tunnel release should be into the brachium, but end more proximally to the medial humeral epicondyle. Attempts to further study the causes of secondary entrapments have not been successful $[28,29,38]$.

The disparity in the frequencies of surgeons finding the SA may be in part due to the differences in dissection methodologies; Bartels et al. [7] suggest that in order to standardise the procedure, a step by step dissection focusing on the fascial coverings should be demonstrated. Otherwise, Bartels et al. [7] report that the findings may be in part by the cut edge becoming more fibrotic, and therefore appearing as a tendinous band, however this secondary observation was not the case for most of the included cases.

Overall, the findings of this analysis suggest that the $S A$ is a common structure, albeit with great variability in terms of morphology, relation to the ulnar nerve, or otherwise atypical. It is not likely to be the primary site for nerve entrapment, but it is largely implicated in post transposition syndrome [14]. To reduce the likeliness of a secondary compression, the ulnar nerve must be adequately mobilized from the SA or otherwise any soft tissue attachments that may cause compression [37].

Although a thorough risk of bias assessment was completed, and the quality of the analysed data was evaluated, this study is still subject to the limitations of the availability of the previously published studies. Since the SL is not frequently found, large scale studies cannot be realistically executed, thus potentially reducing the effects of bias altogether. Fortunately, the statistical power of this meta-analysis enabled appropriate conclusions to be drawn. The disagreements regarding the SA (such as its involvement in entrapment, or its existence altogether) added to the difficulty in the investigation, as the findings tended to be bimodal - either largely present, or completely absent. However, with a comprehensive study, and efforts to explicate the discrepancies, statistically significant values could be obtained. 


\section{CONCLUSIONS}

Since some of the upper limb entrapment peripheral neuropathies have been reported in association with the presence of the SL or the SA, a clinical picture of these two structures must be established in practice. Although the presence of the SL is infrequent, and the manifestation of the SA is highly variable, they are still important considerations in treatment of the aforementioned condition. The SL had a PPE of $1.8 \%$ overall, and may be found minimally more likely on the right side (55.8\%) than the left (44.2\%), but seems to always insert into the medial humeral epicondyle. It was associated with median nerve compression in one of the two studies on the matter. The SA is a valid anatomical structure, and has an overall PPE of $52.6 \%$. Although most typically presenting as a musculotendinous band, it has extensive variability, and may be problematic in procedures involving the anterior transposition of the ulnar nerve. In view of the foregoing, a better understanding of each may be beneficial for the best patient outcomes.

\section{Acknowledgements}

The study was supported by "The Best of the Best! 3.0 (Najlepszy z Najlepszych! 3.0)" grant from the Polish Ministry of Science and Higher Education.

Krzysztof A. Tomaszewski was supported by the Polish Ministry of Science and Higher Education grant for young scientists.

We would like to express our gratitude to $\mathrm{Mr}$ Jacenty Urbaniak for taking the anatomical pictures presented in this work.

\section{REFERENCES}

1. Al-Naib I. Humeral supracondylar spur and Struthers' ligament. A rare cause of neurovascular entrapment in the upper limb. Int Orthop. 1994; 18(6): 393-394, doi: 10.1007/BF00187089, indexed in Pubmed: 7698874.

2. Al-Qattan MM, Murray KA. The Arcade of Struthers: An Anatomical Study. J Hand Surg. 1991; 16(3): 311-314, doi: 10.1016/0266-7681(91)90059-w.

3. Al-Qattan MM, Husband JB. Median nerve compression by the supracondylar process: a case report. J Hand Surg Br. 1991; 16(1): 101-103, doi: 10.1016/0266-7681(91)90142-b, indexed in Pubmed: 2007799.

4. Andreisek G, Crook DW, Burg D, et al. Peripheral neuropathies of the median, radial, and ulnar nerves: MR imaging features. Radiographics. 2006; 26(5): 1267-1287, doi: 10.1148/rg.265055712, indexed in Pubmed: 16973765.

5. Aydinlioglu A, Cirak B, Akpinar F, et al. Bilateral median nerve compression at the level of Struthers' ligament. Case report. J Neurosurg. 2000; 92(4): 693-696, doi: 10.3171/ jns.2000.92.4.0693, indexed in Pubmed: 10761661.
6. Ay S, Bektas U, Yilmaz C, et al. An unusual supracondylar process syndrome. J Hand Surg Am. 2002; 27(5): 913-915, doi: 10.1053/jhsu.2002.34309, indexed in Pubmed: 12239685.

7. Bartels RH, Grotenhuis JA, Kauer JMG. The arcade of Struthers: an anatomical study. Acta Neurochir (Wien). 2003; 145(4): 295-300, doi: 10.1007/s00701-003-0006-5, indexed in Pubmed: 12748890.

8. Bilecenoglu B, Uz A, Karalezli N. Possible anatomic structures causing entrapment neuropathies of the median nerve: an anatomic study. Acta Orthop Belg. 2005; 71(2): 169-176, indexed in Pubmed: 16152850.

9. Blakeborough A, Chennells PM, Cape J. Case report: cellist's elbow? - vascular entrapment in association with the ligament of Struthers. Clin Radiol. 1994; 49(12): 902-904, doi: 10.1016/s0009-9260(05)82891-0, indexed in Pubmed: 7828404.

10. Bradshaw DY, Shefner JM. Ulnar neuropathy at the elbow. Neurol Clin. 1999; 17(3): 447-461, doi: 10.1016/s07338619(05)70147-x, indexed in Pubmed: 10393748.

11. Caetano EB, Sabongi JJ, Vieira LA, et al. Struthers' ligament and supracondylar humeral process: an anatomical study and clinical implications. Acta Ortop Bras. 2017; 25(4): 137-142, doi: 10.1590/1413-785220172504168330, indexed in Pubmed: 28955169.

12. Caetano EB, Sabongi Neto JJ, Vieira LA, et al. The arcade of Struthers: an anatomical study and clinical implications. Rev Bras Ortop. 2017; 52(3): 331-336, doi: 10.1016/j.rboe.2016.07.006, indexed in Pubmed: 28702393.

13. Camerlinck M, Vanhoenacker FM, Kiekens G. Ultrasound demonstration of Struthers' ligament. J Clin Ultrasound. 2010; 38(9): 499-502, doi: 10.1002/jcu.20700, indexed in Pubmed: 20931650.

14. Campbell WW, Landau ME. Controversial entrapment neuropathies. Neurosurg Clin N Am. 2008; 19(4): 597-608, vi, doi: 10.1016/j.nec.2008.07.001, indexed in Pubmed: 19010284.

15. Caputo AE, Watson HK. Subcutaneous anterior transposition of the ulnar nerve for failed decompression of cubital tunnel syndrome. J Hand Surg Am. 2000; 25(3): 544-551, doi: 10.1053/jhsu.2000.6005, indexed in Pubmed: 10811760.

16. Dellon A. Musculotendinous variations about the medial humeral epicondyle. J Br Soc Surg Hand. 1986; 11(2): 175-181, doi: 10.1016/0266-7681(86)90254-8.

17. Dellon A, Mackinnon S. Musculoaponeurotic variations along the course of the median nerve in the proximal forearm. J Hand Surg. 1987; 12(3): 359-363, doi: 10.1016/0266-7681(87)90189-6.

18. Eversman W. Entrapment and compression neuropathies. In: Green D, editor. Operative hand surgery, Vol. 2. Churchill Livingstone, New York 1993: 1341-1385.

19. Gessini L, Jandolo B, Pietrangeli A. Entrapment neuropathies of the median nerve at and above the elbow. Surg Neurol. 1983; 19(2): 112-116, doi: 10.1016/00903019(83)90405-6, indexed in Pubmed: 6845137.

20. Gonzalez MH, Lotfi P, Bendre A, et al. The ulnar nerve at the elbow and its local branching: an anatomic study. J Hand Surg Br. 2001; 26(2): 142-144, doi: 10.1054/ jhsb.2000.0532, indexed in Pubmed: 11281666. 
21. Gunther SF, DiPasquale D, Martin R. Struthers' ligament and associated median nerve variations in a cadaveric specimen. Yale J Biol Med. 1993; 66(3): 203-208.

22. Henry BM, Tomaszewski KA, Walocha JA. Methods of Evidence-Based Anatomy: a guide to conducting systematic reviews and meta-analysis of anatomical studies. Ann Anat. 2016; 205: 16-21, doi: 10.1016/j. aanat.2015.12.002, indexed in Pubmed: 26844627.

23. Henry BM, Tomaszewski KA, Ramakrishnan PK, et al. Development of the anatomical quality assessment (AQUA) tool for the quality assessment of anatomical studies included in meta-analyses and systematic reviews. Clin Anat. 2017; 30(1): 6-13, doi: 10.1002/ca.22799, indexed in Pubmed: 27718281.

24. Kane E, Kaplan EB, Spinner M. [Observations of the course of the ulnar nerve in the arm]. Ann Chir. 1973; 27(5): 487-496, indexed in Pubmed: 4712764.

25. Kleinman WB. Revision ulnar neuroplasty. Hand Clin. 1994; 10(3): 461-477, indexed in Pubmed: 7962151.

26. Laha RK, Dujovny M, DeCastro SC. Entrapment of median nerve by supracondylar process of the humerus. Case report. J Neurosurg. 1977; 46(2): 252-255, doi: 10.3171/ jns.1977.46.2.0252, indexed in Pubmed: 833644.

27. Mirza A, Mirza JB, Lee BK, et al. An anatomical basis for endoscopic cubital tunnel release and associated clinical outcomes. J Hand Surg Am. 2014; 39(7): 1363-1369, doi: 10.1016/j.jhsa.2014.04.030, indexed in Pubmed: 24881897.

28. Ochiai N, Hayashi T, Ninomiya S. High ulnar nerve palsy caused by the arcade of struthers. J Hand Surg. 2016; 17(6): 629-631, doi: 10.1016/0266-7681(92)90188-8.

29. Popinchalk SP, Schaffer AA. Physical examination of upper extremity compressive neuropathies. Orthop Clin North Am. 2012; 43(4): 417-430, doi: 10.1016/j. ocl.2012.07.011, indexed in Pubmed: 23026457.

30. Poujade T, Hanouz N, Lecoq B, et al. Ultrasound-guided surgical treatment for ulnar nerve entrapment: a cadaver study. Chir Main. 2014; 33(4): 256-262, doi: 10.1016/j. main.2014.05.006, indexed in Pubmed: 24981578.

31. Rogers MR, Bergfield TG, Aulicino PL. The failed ulnar nerve transposition. Etiology and treatment. Clin Orthop Relat Res. 1991(269): 193-200, indexed in Pubmed: 1864038.

32. Siqueira MG, Martins RS. The controversial arcade of Struthers. Surg Neurol. 2005; 64 (Suppl 1): S17-S20, doi: 10.1016/j.surneu.2005.04.017, indexed in Pubmed: 15967222.
33. Smith RV, Fisher RG. Struthers ligament: a source of median nerve compression above the elbow. Case report. J Neurosurg. 1973; 38(6): 778-779, doi: 10.3171/ jns.1973.38.6.0778, indexed in Pubmed: 4710659.

34. Spinner M, Kaplan EB. The relationship of the ulnar nerve to the medial intermuscular septum in the arm and its clinical significance. Hand. 1976; 8(3): 239-242, doi: 10.1016/0072-968x(76)90008-5, indexed in Pubmed: 976822 .

35. Suranyi L. Median nerve compression by Struthers ligament. J Neurol Neurosurg Psychiatry. 1983; 46(11): 1047-1049, doi: 10.1136/jnnp.46.11.1047, indexed in Pubmed: 6655479.

36. Taylor Gl, Cichowitz A, Ang SG, et al. Comparative anatomical study of the gracilis and coracobrachialis muscles: implications for facial reanimation. Plast Reconstr Surg. 2003; 112(1): 20-30, doi: 10.1097/01.PRS.0000065909.86735. F7, indexed in Pubmed: 12832872.

37. Tiyaworanan P, Jianmongkol $S$, Thammaroj T. Anatomical study of arcade of Struthers. Hand Surg. 2010; 15(3): 157-159, doi: 10.1142/S0218810410004941, indexed in Pubmed: 21089187.

38. Tubbs RS, Deep A, Shoja MM, et al. The arcade of Struthers: An anatomical study with potential neurosurgical significance. Surg Neurol Int. 2011; 2: 184, doi: 10.4103/21527806.91139, indexed in Pubmed: 22276238.

39. von Schroeder HP, Scheker LR. Redefining the "Arcade of Struthers". J Hand Surg Am. 2003; 28(6): 1018-1021, doi: 10.1016/s0363-5023(03)00421-0, indexed in Pubmed: 14642520.

40. Wehrli L, Oberlin C. The internal brachial ligament versus the arcade of Struthers: an anatomical study. Plast Reconstr Surg. 2005; 115(2): 471-477, doi: 10.1097/01.prs.0000150144.73603.24, indexed in Pubmed: 15692352.

41. Yoshida A, Okutsu I, Hamanaka I. Minimally invasive endoscopic ulnar nerve assessment and surgery for cubital tunnel syndrome patients - relation between endoscopic nerve findings and clinical symptoms. Asia-Pacific J Sport Med Arthrosc Rehabil Technol. 2014; 1(3): 96-101, doi: 10.1016/j.asmart.2014.01.003.

42. Zhong S, Zhong Z, Yu Yu, et al. Ultrasonic observation and clinical application of arcade of struthers in the Mid-Arm. World Neurosurg. 2016; 91: 560-566.e1, doi: 10.1016/j. wneu.2016.03.061, indexed in Pubmed: 27032522. 